horse road was destroyed in quarrying the material from which the bridge was built. The bridge now bears the inscription, "Restored 1932, J. H. Price", to commemorate the fact that the restoration was carried out on the initiative and under the supervision of $\mathrm{Mr}$. Price. As previously mentioned, the workmen were volunteers from the unemployed, and material was given or lent by local contractors.

\section{Undeciphered Scripts}

According to a letter from Sir Denison Ross in the Times of Sept. 21, M. Guillaume Hevesy, a Hungarian resident in Paris, has discovered that a number of the signs of the prehistoric Indian script on seals from Mohenjo-daro also appear in the script of the Easter Island inscribed wooden tablets, while some of the Easter Island signs, not present on the Indian seals, are to be found in the proto-Elamic of Susa. It would now be interesting to hear whether there is any coincidence in the interpretation of the prehistoric Indian signs suggested by Sir Flinders Petrie (see Nature, Sept. 17, p. 429) and those suggested for the Easter Island script in the Report of the Committee of the Royal Anthropological Institute of which Mr. Sidney Ray was chairman. The suggestion of a connexion between the two scripts is not the only attempt to find an affinity between Easter Island and this part of Asia. M. J. Hackin, of the Musée Guimet, has recently directed attention to the resemblance which has been noted between the wooden statues, probably ancestral, which were objects of reverence among the Kafirs of Afghanistan before they were overwhelmed by Islam, of which examples are now preserved in the Kabul Museum, and the well-known statues of Easter Island. The resemblances certainly are strong, although it might be argued that they do not go beyond what may be due to the limitations of an undeveloped technique. It must also be admitted that when the material which it is sought to bring into relation is so widely separated in date as in these instances, the comparison, in default of intervening links, carries more interest than conviction.

\section{The Development and Use of Talking Films}

EVERY improved facility of communication has profoundly affected civilisation. The telegraph and the telephone and the widening of their scope by radio waves have benefited mankind. In the Journal of the Franklin Institute for August, H. M. Wilcox points out that the latest outcome of science, the talking film, has many useful applications for social and educational purposes which are not yet fully recognised. For example, a test was recently conducted at the Teachers College, Columbia University, to find the relative values of private study and seeing and hearing a talking film. Certain highly technical aspects of the training of teachers were presented by a talking film which lasted twenty minutes. Half of a group of students attended this, whilst the other half were given the monograph from which the film was constructed to study for half a day, but did not see the picture. A subsequent examination showed that the former group attained considerably higher marks than the latter. The author also lays stress on the fact that the talking film can democratise education in much the same way as it has democratised the dramatic stage. The great teacher can be taken to students in the most remote districts, and material presented to them which hitherto has been available only for the chosen few.

Mr. Wilcox also shows how highly technical are the problems of recording and reproducing sounds. Sound is judged by its pitch, volume, and quality (timbre). The pitch is measured by the frequency, the range being $16-16,000$ cycles per second, and is frequently called the sound spectrum. The volume or loudness is measured in terms of energy intensity or pressure. Since the ear hears logarithmically, this is expressed in terms of logarithmic units called decibels. One decibel is approximately the smallest change in volume which the ear can detect. The quality depends on the presence of overtones, the frequency of which is an integral multiple of the fundamental tone. Male speech has a range of 100 . 250 cycles, and female speech, $200-500$ cycles. Practically none of the characteristics of speech by which we recognise one articulate sound from another is particularly influenced by varying the fundamental. Early experience with talking films proved that, unlike silent films, the acoustic properties of the theatre itself had to be taken into account. This showed that both qualitative and quantitative acoustic measurements had to be made. This has led to the development of special instruments, the frequency analyser, the level analyser, the reverberation meter, and the noise meter, which are now successfully used for analysing the acoustic conditions in theatres, and in many other places as well. The success of the recent piano recital by Paderewski before an audience of 16,000 in Madison Square Garden without the use of any sound amplifying device shows what can be done by proper acoustic treatment.

\section{The Swiss Broadcast Network}

Practical experience seems to prove that radio transmission can only be utilised to its greatest advantage when wire connexions are used in part of the circuit. In the early days radio was a competitor with wire transmission, but now it co-operates with it, the co-operation being to their mutual advantage. The transmitting stations in a broadcast system are situated outside the cities where the studios are situated, and are connected to them by wires. In Electrical Communication for July, A. Muri, chief engineer of the postal administration at Berm, gives an interesting account of the Swiss broadcast network. For broadcasting purposes, Switzerland is divided into three zones. For French-speaking Switzerland, the main transmitter is at Sottens and is fed by thestudios at Lausanne and Geneva. For German-speaking Switzerland, the main transmitter is at Beromünster and there are two relay transmitters at Bern and Basel. All three transmitters broadcast the same programme, and are fed from the studios at Zurich, Berm, and Basel as required. The main transmitter for Italian-speaking Switzerland is still under construction at Monte Ceneri. When completed it will be 